\title{
Household Purposes in a Single Touch via Bluetooth Using Smartphones
}

\author{
Bhavani Rohit ${ }^{1}$, Rengamani J. ${ }^{2}$ \\ ${ }^{1}$ Research Scholar, AMET Business School, AMET University, Chennai \\ ${ }^{2}$ Associate Professor, AMET Business School, AMET University, Chennai
}

\begin{tabular}{l}
\hline Article Info \\
\hline Article history: \\
Received Oct 28, 2017 \\
Revised Dec 31, 2017 \\
Accepted Jan 20, 2018 \\
\hline
\end{tabular}

Keywords:

Bluetooth

Household Devices

IR

Mobile Applications

Remotes

Wi-Fi

\begin{abstract}
Technology emerges in our environment day by day. But, still, we lag in keep on using multiple remotes for every device in our homes. Once Bluetooth came up it changes. People started using mobile phones connected to their devices to hear songs wireless and change channels using a mobile phone. A further implementation is kept on moving with multiple remotes for their usage. So, we had an idea that all our household devices may be controlled on our mobile phones via Bluetooth which is cheaper even for urban peoples. Now, all home devices with remote are IR based which doesn't work on sunlight, fluorescent bulbs due to interference. Switch over Bluetooth control reduces remotes in a sense called plastics. Mobile applications are evolved user-friendly to all the people on the day to day lives. Merge those applications to the household devices to control all household devices operated via remote such as TV, DVD, Home theatres, $\mathrm{AC}$, even Table fan etc., Instead of removing IR's just interface Bluetooth chip on those household devices to control every remote device by using your smartphone. Why I am moving to Bluetooth instead of Wi-Fi. Bluetooth is cheaper, advanced to control devices in the range of 50 meters. But IR is useful to 10 meters, and once you block the signal, it will not work.
\end{abstract}

Copyright $@ 2018$ Institute of Advanced Engineering and Science. All rights reserved.

\section{Corresponding Author:}

Bhavani Rohit,

Research Scholar, AMET Business School,

AMET University,

Chennai.

\section{INTRODUCTION}

Remote applications are the one which helps consumers to do what they need from their premises without moving a bit [1]. It changes totally from wired to wireless. When in the old days they use a wired remote to change a channel, volumes of their television. Which is then updated with IR signals and the range is increased accordingly per period [2]. Even though the technology update satisfies some, but it remains unsatisfaction for many who control all those devices multiple times with multiple remotes. Suffer from searching where they kept it, and keep on using different remotes for various devices keep them tensed up [3].

Updated of mobile phone controlling television and DVD players keep them boosted up but it did not emerge soon with the current environment. Think of people, who broke remotes on anger, because they believe it is cheap and will be bought for a small budget [4]. But think of plastic emerging into our lives and cause various disease of using plastic. Once we move on using mobile phones, so reduce the amount of using multiple remotes every time and use your cell phone [5] as a remote and access multiple devices at a time using one smartphone. Critical analysis of harmful gases from flue gas is presented in [6]. 


\section{PROPOSED WORK}

Our proposed work briefly describes the household devices controlled with a single remote which is a smartphone via Bluetooth. In Figure 1, the home devices are controlled by remotes which can be controlled by Bluetooth phone by interfacing those devices with Bluetooth chips increase the efficiency of using a smartphone as a remote to control all devices with remote functions. Power Consumption Modeling and Analysis of Integrated Optical-Wireless Access Network discussed in [7].

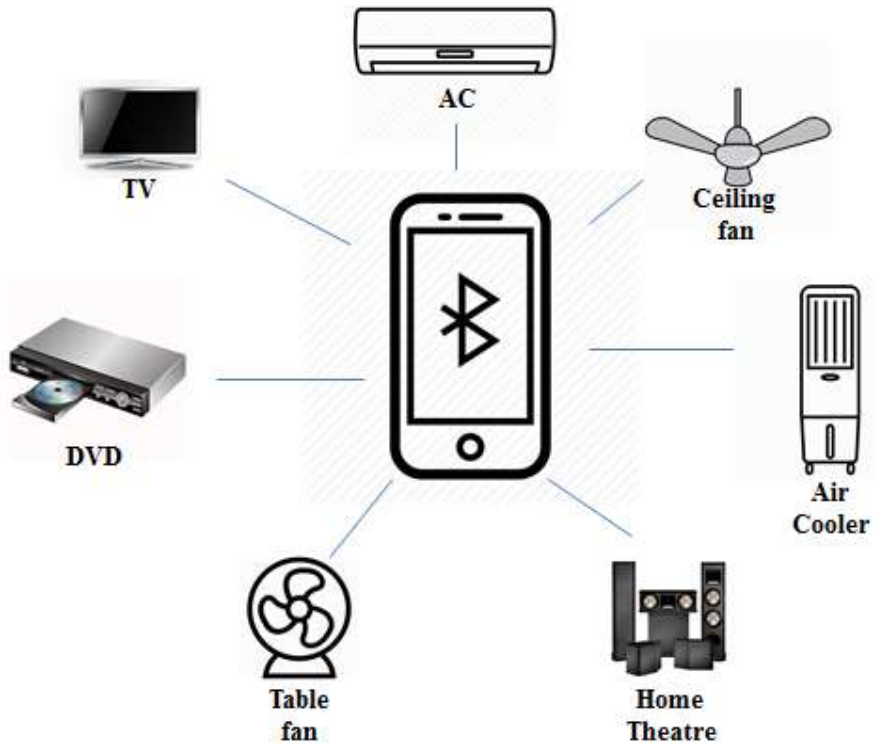

Figure 1. Architecture

Nowadays, a mobile application can access any household devices with the help of Bluetooth interface implemented on the home devices like a smart work. Once you move on to smartphones, there is no need of searching for each remote to control devices on your home. Just take your phone, open application and monitoring devices on touch. Even they implemented ceiling fan to control via remote. To improve efficiency in smart work needed an upgrade version of household devices with Bluetooth chips.

Remotes were working on the principle of codes which is then converted to signal by remote and on-device side it is then decoded to codes to change a frequency of channel or volume of your device. It depends on the signal generated for each button on the remote has a unique code that will not alternate. But each brand has its code that's y Sony remote won't work on Samsung TV. Each brand has a unique way of code for their perspective devices to only control by their brand of remotes.

Instead of using multiple remotes for various devices, a Bluetooth phone can access all remote devices using remote applications on your phone as a device friendly. Using smartphones via Bluetooth the code is sent to the own brand TV that will enormously work under any circumstances like sunlight, fluorescent bulbs etc., It won't deviate on interference, radio frequencies quickly transmit those codes even they have been blocked. Intelligent Management on the Home Consumers with Zero Energy Consumption discussed in [8]. Wireless channel with a range of 50 meters minimum can have an access even you are in a closed room. Astrobell for Modern Smart Home discussed in [9],[10].

\section{RESULT AND DISCUSSION}

Old days wired remote emerged but not so long. Because, the wired has some limited range, which is inconvenient to the consumers. Later IR launched into the market, and it satisfies customers more on that period which is wireless. Development of a Wireless Sensor Network for Greenhouse Monitoring and Control discussed in [11]. Now, Bluetooth is come up with additional features and low-budget cost which is also effective for urban peoples to use advanced technology cheaper for their budget. 


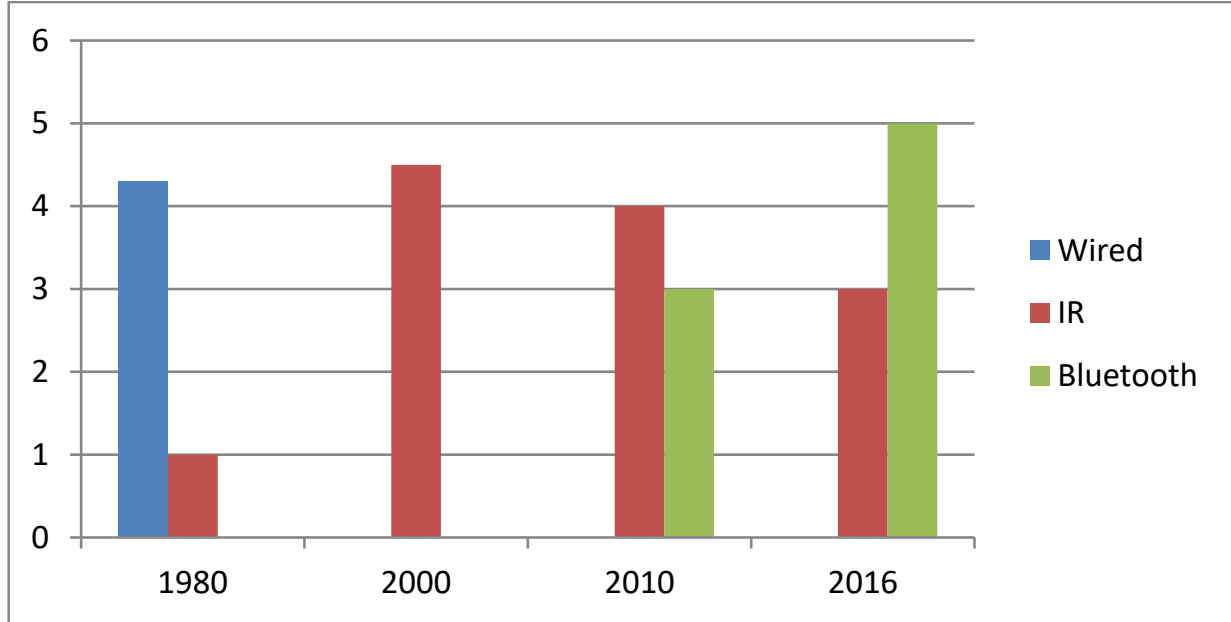

Figure 2. Comparison of Wired and Wireless Among Years

\section{CONCLUSION}

Technology is emerging day by day to create innovation that satisfies the consumers using their products. Sometimes upgrade is needed to change something different to our environment. Thereby, Bluetooth is cheaper for even urban people to use advanced technology with their budget. Preference is on top to the product which satisfies all.

\section{REFERENCES}

[1] N. H. Saleem, "Applying Bluetooth as Novel Approach for Assessing Student Learning," Computer Science Institute, Sulaimani Polytechnic University, IRAQ, Asian Journal of Natural \& Applied Sciences, vol/issue: 4(2), 2015.

[2] H. K. Su, et al., "A Hybrid Indoor-Position Mechanism Based on Bluetooth and WiFi Communications for Smart Mobile Devices," Dept. of Electrical Engineering National Formosa University No. 64, Wenhua Rd., Huwei, Yunlin 632, Taiwan (R.O.C.).

[3] A. Banerjee, "A Bluetooth Messenger Application," Department of Computer Science National Institute of Technology, Rourkela, 2015.

[4] Q. Gong, et al., "Design and Implementation of Pulse Signal Detection System Based on Bluetooth Transmission, School of Mechanical, Electrical and Information Engineering, Shandong University, Weihai, 264209, China," International Journal of Control and Automation, vol/issue: 8(7), pp. 141-148, 2015.

[5] S. Ahmad, et al., "Bluetooth an Optimal Solution for Personal Asset Tracking: A Comparison of Bluetooth, RFID and Miscellaneous Anti-lost Tracking Technologies, School of Management and Economics University of Electronic Science and Technology of China," International Journal of $u$ - and e-Service, Science and Technology, vol/issue: 8(3), pp. 179-188, 2015.

[6] Priya T. S. and Balasubramanian V., "Critical analysis of harmful gases from flue gas," Biosciences Biotechnology Research Asia, vol/issue: 11(special edition 1), pp. 35-43, 2014.

[7] A. Ramli, et al., "Power Consumption Modeling and Analysis of Integrated Optical-Wireless Access Network," International Journal of Electrical and Computer Engineering (IJECE), vol/issue: 7(6), 2017.

[8] K. Khani and M. I. Ghiasi, "Intelligent Management on the Home Consumers with Zero Energy Consumption," Indonesian Journal of Electrical Engineering and Informatics (IJEEI), vol/issue: 5(3), 2017.

[9] Amudha S., et al., "SMS Controlled Smart Home System in IOT," International Journal of MC Square Scientific Research (IJMSR), vol/issue: 8(1), pp. 1-8, 2016.

[10] Kayalvizhi S., “Astrobell for Modern Smart Home," International Journal of MC Square Scientific Research (IJMSR), vol/issue: 8(1), pp. 9-15, 2016.

[11] M. Mekki and O. Abdallah, "Development of a Wireless Sensor Network for Greenhouse Monitoring and Control," Indonesian Journal of Electrical Engineering and Informatics (IJEEI), vol/issue: 5(3), 2017. 